\title{
An Update and Practical Guide to Renal Stone Management
}

\author{
Nikhil Johri $^{a}$ Bruce Cooper ${ }^{d}$ William Robertson ${ }^{a}$ Simon Choong ${ }^{c}$ \\ David Rickards $^{\mathrm{b}}$ Robert Unwin ${ }^{\mathrm{a}}$ \\ ${ }^{a}$ Centre for Nephrology, UCL Medical School, Royal Free Campus, and Departments of b Radiology and \\ 'Urology, University College Hospital, London, UK; ${ }^{\mathrm{d}}$ Nephrology Department, Royal North Shore Hospital, \\ Sydney, N.S.W., Australia
}

\section{Key Words}

Kidney $\cdot$ Stones $\cdot$ Urine $\cdot$ Metabolic syndrome $\cdot$ Diabetes . Acidosis

\begin{abstract}
Renal stone disease covers kidney and lower urinary tract stones caused by a variety of conditions, including metabolic and inherited disorders, and anatomical defects with or without chronic urinary infection. Most cases are idiopathic, in which there is undoubtedly a genetic predisposition, but where environmental and lifestyle factors play an important role. Indeed, it is becoming apparent that renal stone disease is often part of a larger 'metabolic picture' commonly associated with type 2 diabetes, obesity, dyslipidaemia, and hypertension. Renal stone disease is a growing problem in the UK (and other developed and developing populations) with a cross-sectional prevalence of $\sim 1.2 \%$. This means that there are currently $\sim 720,000$ individuals with a history of kidney stones in the UK. Almost $40 \%$ of first-time stone formers will form a second stone within 3 years of the first episode if no prophylactic measures are instituted to prevent stone recurrence, since removal or disintegration of the first stone does not treat the underlying cause of stones in the majority of patients. The age of onset is getting younger and the sex ratio (until recently more men than women) is becoming al-
\end{abstract}

most even. Metabolic screening remains an important part of investigating renal stone disease, but to the disappointment and frustration of many doctors, medical treatment is still essentially pragmatic, except perhaps in cystinuria, and to a limited extent in primary hyperoxaluria (if pyridoxinesensitive); although newer treatments may be emerging. This review summarizes current thinking and provides a practical basis for the management of renal stone disease.

Copyright $\odot 2010$ S. Karger AG, Basel

\section{Introduction}

Renal stone disease is common, with a worldwide prevalence of between 2 and 20\% [1-3]. Highest lifetime risk of stone formation has been reported in men in the United Arab Emirates (UAE) and Saudi Arabia (KSA) (fig. 1). Prevalence within Europe ranges more narrowly between 2 and 8\%; however, a recent study in Greece found prevalence as high as $15 \%$ in a rural population in Thebes [4]. Epidemiological studies in the United States show a trend for increasing prevalence in women and those living in more southern latitudes: males in the southeast have a prevalence rate of $12 \%$ compared with $7 \%$ in the northwest [3].

\section{KARGER}

Fax +4161306 1234 E-Mail karger@karger.ch www.karger.com

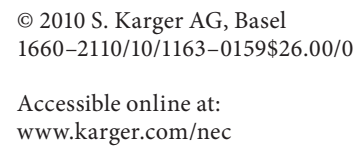

Tel. +44 207472 6499, E-Mail robert.unwin@ucl.ac.uk 
Fig. 1. Lifetime expectancy of stones among men aged $60-70$ years in various countries [adapted from 60].

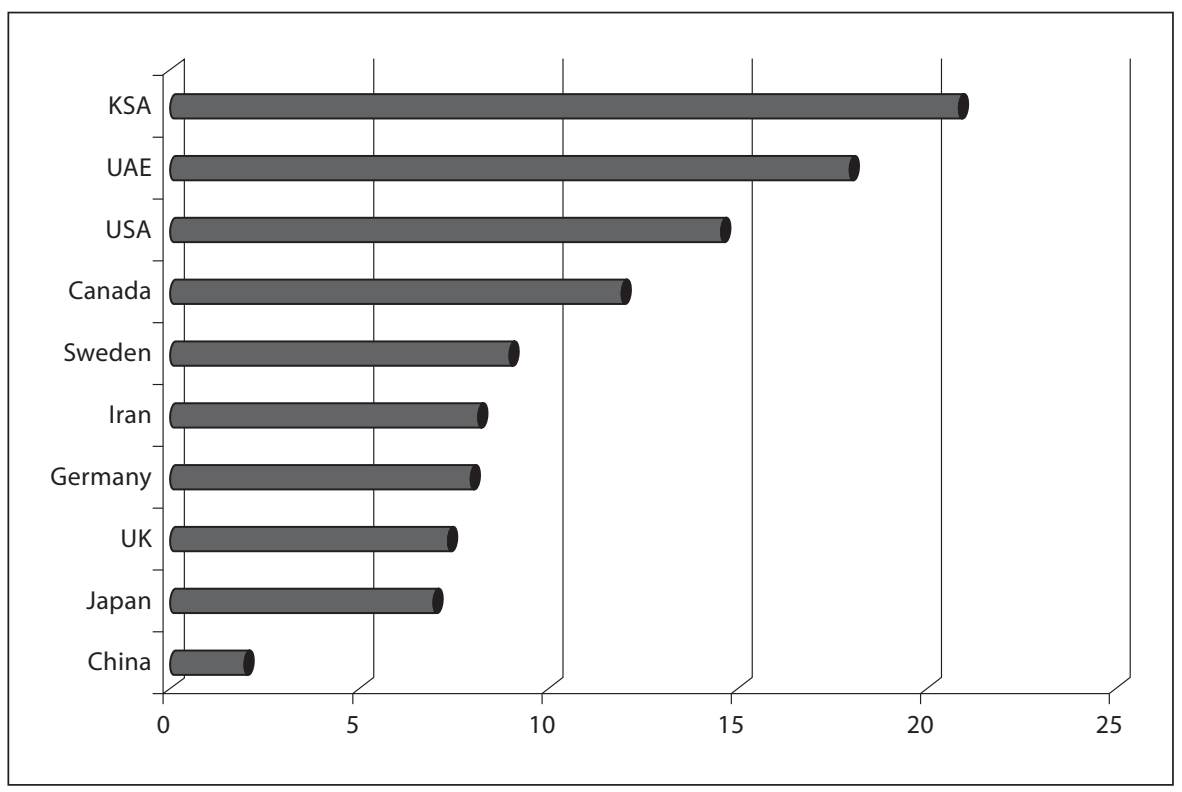

Stone recurrence worldwide is also common: it is estimated that almost $50 \%$ of stone formers will have a recurrence within 10 years [5]. Recurrent stone disease causes not only pain and distress in those affected, but it also imposes a significant economic burden from lost working days and associated healthcare costs. Minimally invasive surgery has revolutionized acute and complex stone management, but it has not reduced recurrence rates because less invasive therapies, including extracorporeal shockwave lithotripsy (ESWL), often result in incomplete stone clearance. However, there is evidence that intervention in the form of lifestyle advice [6] and some forms of medical therapy can reduce the rate of stone recurrence [7]; thus, metabolic investigation and medical treatment are both important elements in the clinical management of renal stone disease. This review summarizes what we currently know and think about renal stone disease, and it sets out a practical approach to renal stone management, based largely on the authors' collective experience.

\section{Pathophysiology}

Renal stone disease is not a single disorder, since stone composition varies, which reflects constitutional, environmental, and genetic factors (cystine stones are probably the most common genetic type seen in adult clinical practice). Table 1 lists the main types of renal stone and their relative prevalence.
Table 1. Composition and relative prevalence of the main renal stone types

Calcium oxalate stones (pure) or with small amounts of calcium phosphate

$59 \%$

Predominantly calcium phosphate stones $\quad 10 \%$

Uric acid stones

$17 \%$

Struvite or infection stones

$\begin{array}{lr}\text { Cystine and other stones } & 2 \%\end{array}$

The physico-chemical theory of stone formation considers urine as a supersaturated solution in which homogeneous or heterogeneous nucleation can lead to initiation of crystal formation, which can then aggregate and grow. However, incompletely understood biological processes can anchor these crystals to the urothelium. A widely held theory is that of Randall's plaques, which proposes that subepithelial interstitial calcium-based deposits (the originally described 'Randall's plaques') act as nuclei for stone formation. These plaques, which are composed of apatite (calcium phosphate and not calcium oxalate), originate adjacent to the thin limbs of loops of Henle (which could be related to the high local ion concentrations at this site). As they grow in size, they erode through the renal papillary duct epithelium to provide sites for intratubular calcium oxalate crystal adhesion and growth. Radiological and endoscopic studies have shown that many, but not all, stone formers have Ran- 
dall's plaques $[8,9]$. While this theory might explain the origin of many calcium oxalate stones, the plaques are not evident in non-calcium stones or in all calcium oxalate stone formers, for example, post-gastric bypass surgery. A more recent theory is that surface molecules such as phosphatidylserine, sialic acid, hyaluronan, osteopontin, or the glycoprotein receptor CD44 (involved in cell adhesion), expressed on the luminal membrane of collecting duct epithelial cells, may promote or retard cell membrane-crystal interactions [10-12]. In the presence of these molecules, crystals adhere to the luminal membrane, where they are normally taken up into the cell by endocytosis and degraded or transported into the interstitium (perhaps to form Randall's plaques) [13]. Several in vitro studies have shown that cell injury and repair, or regeneration, increase the surface expression of these molecules, resulting in more crystal adhesion [14], which may form the nidus for eventual stone formation; defective endocytosis may also be a causal factor (e.g. in Dent's disease) [15].

\section{Risk Factors}

Certain environmental and lifestyle factors can increase stone risk. A higher risk is found in professional chefs or others working in hot environments, as well as in taxi drivers who often try to minimize their fluid intake to avoid too many 'toilet stops'.

Diet-related factors that are known to increase stone risk are listed in table 2. Tea or coffee (particularly instant coffee) without milk has been shown to increase oxalate excretion, although this effect is probably offset by their diuretic action [16]. Dietary calcium has a biphasic risk curve: stone risk is greater in those on a high or low calcium diet [17]. The link between vitamin D intake and renal stones is less clear: while excessive active $(1,25-\mathrm{OH})$ vitamin D supplementation, by increasing intestinal calcium absorption, increases the risk of stone formation, there is no evidence that correction of native $(25-\mathrm{OH}) \mathrm{vi}-$ tamin D deficiency has the same effect; moreover, correction, especially if there is secondary hyperparathyroidism, is likely to be a health benefit. Vitamin $\mathrm{C}$ excess could also increase the risk of calcium oxalate stone formation, but in practice this is rarely encountered. High dietary intake of potassium or magnesium is inversely related to stone formation because potassium promotes urinary citrate excretion, and both citrate and magnesium inhibit crystal formation. However, the impact of low urinary magnesium on stone risk is at best modest.
Table 2. Dietary risk factors associated with increased stone risk

\section{Low fluid intake [56]}

High intake of animal protein [56]

High dietary sodium [56]

Excessive intake of refined sugars [57]

Foods rich in oxalate [58]

High intake of grapefruit juice, apple juice [16], and soft cola drinks [59]

Table 3. Non-lifestyle (and non-genetic) factors associated increased stone risk and rates of recurrence

\begin{tabular}{ll}
\hline $\begin{array}{l}\text { Factors associated with } \\
\text { increased stone risk }\end{array}$ & Underlying mechanism(s) \\
\hline $\begin{array}{l}\text { Primary } \\
\text { hyperparathyroidism }\end{array}$ & $\begin{array}{l}\text { Hypercalciuria and hypercalcae- } \\
\text { mia }\end{array}$ \\
\hline Urinary tract infection & $\begin{array}{l}\text { Precipitation of calcium phos- } \\
\text { phate and magnesium ammoni- } \\
\text { um phosphate - struvite stones - } \\
\text { in alkaline urine }\end{array}$
\end{tabular}

Chronic inflammatory bowel Increased oxalate absorption disease

\begin{tabular}{ll}
\hline Ileostomy & $\begin{array}{l}\text { Bicarbonate and fluid losses caus- } \\
\text { ing low urine volume with an } \\
\text { acid urine pH }\end{array}$ \\
\hline $\begin{array}{l}\text { Prolonged immobilization } \\
\text { due to spinal injury or for } \\
\text { other reasons }\end{array}$ & $\begin{array}{l}\text { Hypercalciuria from bone loss } \\
\text { and urinary stasis due to bladder } \\
\text { catheterization in spinal injury }\end{array}$ \\
\hline
\end{tabular}

Other factors associated with increased stone risk are chronic laxative abuse, antacid excess or betel nut chewing (both forms of 'milk-alkali syndrome'), tropical holidays, regular strenuous exercise, and even psychological stress (although how is unclear).

Several non-lifestyle factors can increase the risk of stone formation and recurrence; these, along with the underlying mechanisms, are listed in table 3 . Conditions in which there is insulin resistance, such as obesity, the metabolic syndrome [18], and type 2 diabetes mellitus [19, 20], are now known to be associated with increased stone risk. Insulin resistance may be the underlying cause, as it is linked to reduced renal ammoniagenesis and decreased urinary ammonium excretion relative to net acid excretion, resulting in a more acid urine $\mathrm{pH}$, which favours uric acid and mixed urate-calcium oxalate stone formation [21]. 
Congenital, surgical and anatomical defects causing localized urine stasis and renal stones include medullary sponge kidney, horseshoe kidney, enterocystoplasty, and pelviureteric junction obstruction.

\section{Novel Risk and Genetic Factors}

Colonization of the gut by an oxalate degrading anaerobe, Oxalobacter formigenes, has been linked to reduced oxalate stone risk [22]. It has been shown that these bacteria not only degrade oxalate, but that they also interact (in an as yet unspecified way) with the chloride/oxalate anion exchanger (CFEX, SLC26A6) present in intestinal epithelial cells to increase oxalate secretion and reduce its net absorption [23].

Gastric bypass surgery (Roux-en-Y) is increasingly used to treat widespread obesity (which itself is a risk factor for renal stones). Recent studies have shown increased stone risk following this form of surgery [24], which is due to 'enteric hyperoxaluria' from a combination of disturbed enterohepatic bile circulation and loss of calcium (that normally binds dietary oxalate) through binding to fatty acids, and changes in the gut microflora affecting oxalate absorption.

A positive family history of kidney stones is strongly associated with increased stone risk. Relative risk in those with a positive family history is $2-3$ times higher, and several genetic factors have been proposed that may explain some of this association. Alanine:glyoxylate aminotransferase (AGT) is a key vitamin $\mathrm{B}_{6}$ (pyridoxine)-dependent enzyme found predominantly in liver peroxisomes, where it converts glyoxylate to glycine, reducing the formation of oxalate from glyoxylate. A polymorphism of this enzyme (Pro ${ }^{11} \mathrm{Leu}$ ) has been identified that mistargets some AGT to mitochondria rather than peroxisomes. Peroxisomes deal more effectively with plant-derived glycolate, whereas mitochondria handle meat-derived hydroxyproline, both sources of glyoxylate production. Thus, the Pro ${ }^{11}$ Leu AGT polymorphism may be an advantage to those consuming a high animal protein diet, but a disadvantage for those on a more vegetarian diet [25]; as yet this hypothesis remains untested. The already mentioned novel oxalate transporter CFEX is present in renal and intestinal epithelia, and CFEX null mice have a high incidence of calcium oxalate stones, primarily due to increased oxalate absorption in their small intestine [26]. It is possible that polymorphisms of this transporter may affect oxalate absorption in humans and thereby calcium oxalate stone risk. Other gene polymorphisms that have been linked to increased renal stone risk include the renal sodium-phosphate co-transporters NaPT2a and NaPT2c, the sodium-proton exchanger regulatory factor NHERF1 [27], as well as the renal calcium-sensing receptor [28], and some monogenic disorders such as primary hyperoxaluria (types I and II), Dent's disease, Bartter's syndrome (types I and II), inherited forms of distal renal tubular acidosis (dRTA), and cystinuria.

\section{Investigation of Renal Stones}

Metabolic investigations are important in predicting the likely stone type (if stone material is not available for analysis), in identifying secondary causes and metabolic risk factors, in assessing prognosis, and as a guide to therapy. Ideally, a complete metabolic workup should include fasting blood and spot urine samples, along with nonfasted 24-hour urine collections for analysis. Contemporaneous dietary assessment is useful in interpreting the results of blood and urine analyses and to give tailored dietary advice on how to minimize future stone risk. A 1-week diet diary gives a reasonable average, although a shorter period can still be useful. While a detailed metabolic screen may not be necessary in cases of first presentation with a single stone, it should be considered in those with multiple stones, bilateral stones, uric acid stones, staghorn calculi, nephrocalcinosis, a single kidney, a history of recurrent stones, or in those undergoing workup as prospective live kidney transplant donors and found to have an incidental renal stone ${ }^{1}$. Those with their first kidney stone at an early age ( $<25$ years), or those found to have renal impairment with stones, should also be investigated further. Figure 2 is the clinical management algorithm that we currently use in renal stone disease. Ideally, metabolic screening should be postponed until at least 6 weeks after a stone episode or intervention such as ESWL, percutaneous nephrolithotomy (PCNL) or uretero-renoscopy (URS), since initial compliance with more general measures like increased fluid intake is usually good for the first few weeks after an episode of painful renal colic.

\footnotetext{
1 Whether the finding of an incidental and asymptomatic renal stone should exclude kidney donation is debatable and must depend on the individual circumstances. If the stone is small, single, and unilateral, and/ or can be easily treated by lithotripsy, and the estimated future stone risk is low (see later), then the affected kidney is the one that can be donated; however, all such donors should be monitored indefinitely because of the still finite risk of stone formation in a single kidney.
} 


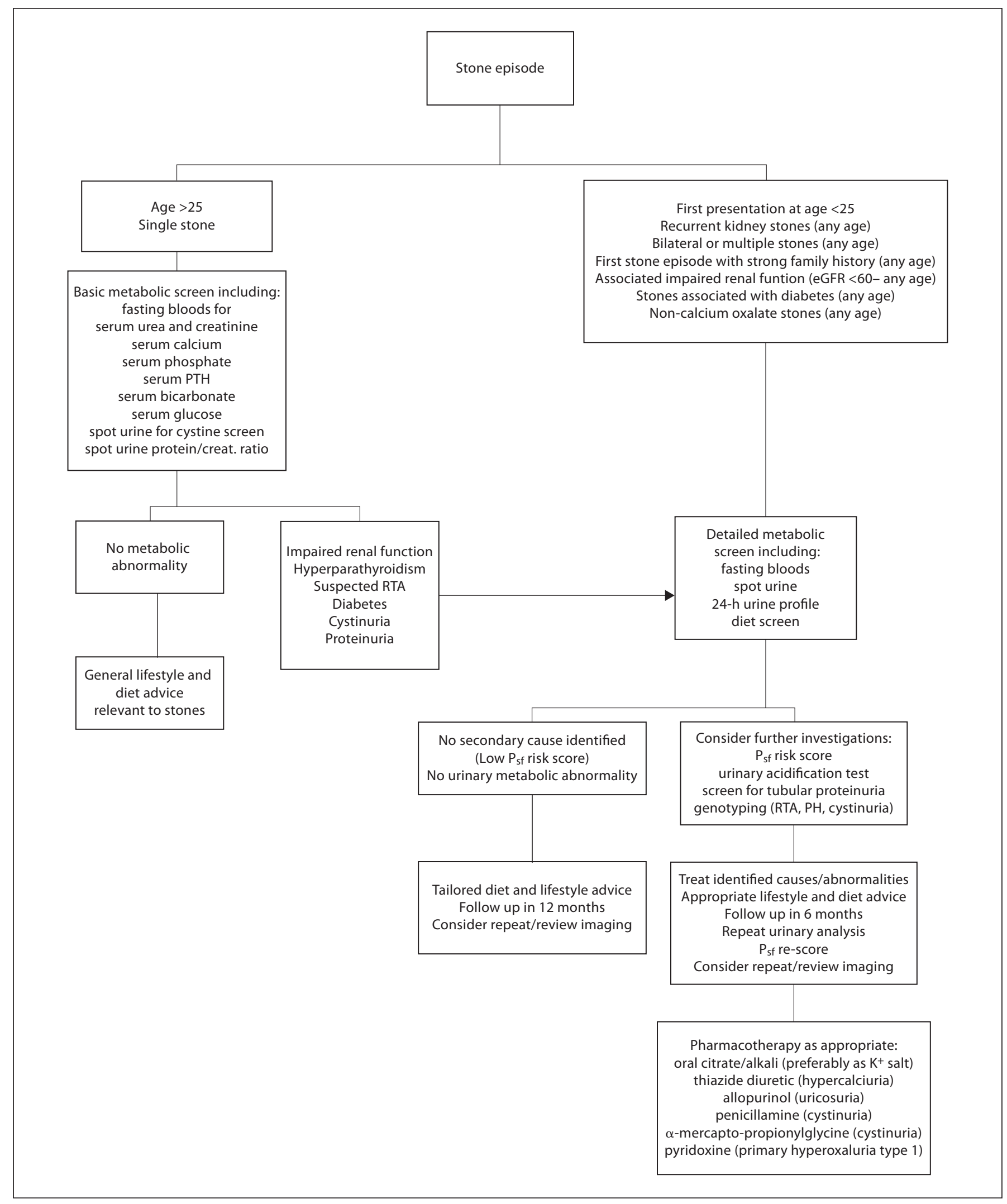

Fig. 2. An algorithm for the metabolic investigation of patients with renal stone(s) (see text for details). 
The value of chemical stone analysis (usually carried out by infra-red spectroscopy and/or quantitative wet analysis) cannot be overemphasized; although it does not replace metabolic investigations, it can add to or confirm any findings and help in their interpretation. Unfortunately, in most stone clinics, renal stone analysis is available in only 30 or $40 \%$ of cases. This is because small stones are often passed without the patient realizing it, or because of the difficulties in trying to collect stone material after lithotripsy.

Routine blood tests should include urea, creatinine, electrolytes, glucose, chloride, bicarbonate, uric acid, calcium, phosphate, magnesium, parathyroid hormone and vitamin $\mathrm{D}$. These blood values help to establish baseline renal function and can detect primary or secondary hyperparathyroidism, hyperchloraemic metabolic acidosis, and features of the metabolic syndrome, including impaired glucose tolerance. Spot fasting urine testing should include $\mathrm{pH}$, electrolytes, protein, and a qualitative cystine screen. Screening urine for retinol-binding protein and $\mathrm{N}$-acetylglucosamine are useful in patients with a suspected underlying proximal tubulopathy (e.g. Fanconi syndrome or Dent's disease). Urine dipstick testing is helpful in detecting blood, protein, leukocyte esterase and nitrites ${ }^{2}$. If positive, microscopy and urine culture screening for infection should be considered; however, in patients with kidney stones or fragments still in situ, dipstick testing is often positive for blood, protein and esterase without infection.

Urine $\mathrm{pH}$ is a key determinant of stone formation, but it can vary widely before and after meals; measurement on a fasting early-morning (second void) sample reduces variability. Urinary infection with urea-splitting organisms like Proteus, Klebsiella or Pseudomonas species can increase urine $\mathrm{pH}$ by generating ammonium to produce stones composed of ammonium-magnesium-phosphate; these stones are also found in chronic laxative abuse (sometimes a clue to an underlying eating disorder), which causes potassium depletion that stimulates ammoniagenesis and reduces citrate excretion. When adjusted for diet, which can be used to calculate a predicted urine $\mathrm{pH}$ [29], an 'inappropriately' acid urine $\mathrm{pH}$ is often found in uric acid and calcium oxalate stone formers with underlying metabolic syndrome or type 2 diabetes mellitus (see fig. 3 ).

Samples from 24-hour urine collections should be analyzed for volume, $\mathrm{pH}$, calcium, phosphate, magnesium,

\footnotetext{
2 Use of a routine clinic urine dipstick to measure urine $\mathrm{pH}$ is inaccurate and should not be used for reliable urine $\mathrm{pH}$ measurements.
}

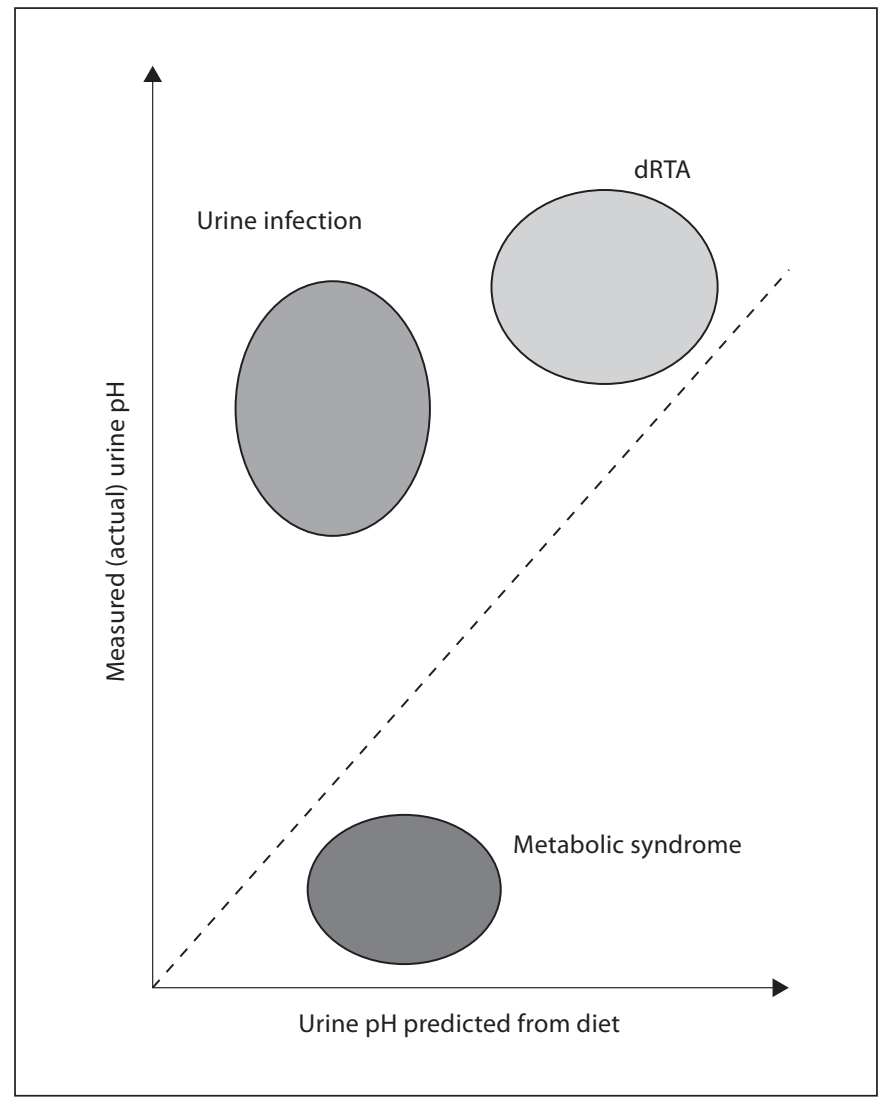

Fig. 3. Predicted (according to diet) versus measured urine $\mathrm{pH}$ (see text) [29]. Most stone formers fall on the line of identity, but certain groups, as shown, do not. This form of graphical analysis can prove useful in determining further investigations and in guiding therapy: above the dashed line, more alkaline than predicted; below the dashed line, more acid than predicted.

oxalate, citrate, urate and electrolytes $\left(\mathrm{Na}^{+}, \mathrm{K}^{+}\right.$and $\left.\mathrm{Cl}^{-}\right)$, creatinine and urea (a useful index of dietary protein intake). Urinary electrolytes can be used to calculate the urine anion gap to estimate urinary ammonium $\left(\mathrm{NH}_{4}{ }^{+}\right)$, which is often reduced in renal tubular acidosis (RTA) or type 2 diabetes ('metabolic syndrome'). Two or more 24hour collections on consecutive days help to achieve better averaging, since analyte concentrations tend to vary from day to day. The first 24-hour collection is made in an acid-containing bottle $(\mathrm{pH}<2)$ for a more accurate estimate of urinary oxalate. Urine acidification prevents precipitation of calcium oxalate crystals and interference from vitamin $\mathrm{C}$ in colorimetric-enzymatic assays. The second collection is made in a plain container to measure average 24 -hour $\mathrm{pH}$, uric acid and protein concentrations.

Urinary citrate is an inhibitor of crystallization of calcium salts in urine, and studies have linked lower levels 
of urinary citrate excretion to increased calcium oxalate stone risk [30]. Urinary citrate levels of $<2.0 \mathrm{mmol} /$ day in males and $<2.5 \mathrm{mmol} /$ day in females are considered abnormal. A low urinary citrate occurs with metabolic acidosis (e.g. in distal or type $1 \mathrm{RTA}^{3}$ ) and with chronic potassium depletion. Low urinary citrate excretion is also commonly found in those with a high dietary intake of animal protein (a high acid-ash diet), whereas vegetarians (a high alkaline-ash diet) tend to have higher levels of citrate excretion.

In idiopathic calcium oxalate stone formers, hypercalciuria is the commonest metabolic abnormality [31]. Stone risk is a continuum that increases with increasing concentrations of urinary calcium and oxalate. Any cut-offs are largely dependent on the reference population and analytical methods used, but urinary calcium excretion $>6.0$ $\mathrm{mmol} / 24 \mathrm{~h}$ is considered abnormal in stone formers, and a reduction can reduce rates of stone recurrence. Before diagnosing 'idiopathic hypercalciuria', primary hyperparathyroidism, vitamin D excess, milk-alkali syndrome, multiple myeloma and malignancy should be excluded; high dietary sodium also increases urinary calcium excretion. Hypercalciuria in dRTA is really only seen in those patients who are acidotic (so-called 'complete' dRTA) with serum bicarbonate concentrations $<20 \mathrm{mmol} / \mathrm{l}$.

Idiopathic hypercalciuria patients have been subdivided into those who have increased intestinal absorption ('hyperabsorptive hypercalciuria') and those who have increased renal losses ('renal hypercalciuria'); however, this classification provides no insights into the underlying mechanisms, or helps in the management, of idiopathic hypercalciuria. Moreover, urinary oxalate is the critical factor in calcium oxalate stone formation because its concentration is much less than that of urinary calcium. This means that a small decrease in urinary oxalate will have a much greater impact on the reduction in stone risk than a decrease in urinary calcium. Urinary oxalate levels of $>450 \mu \mathrm{mol} /$ day are considered abnormal. A variable amount of urinary oxalate is derived from the diet (10$20 \%$ ), which depends on oxalate intake, intestinal absorption (and excretion), and concomitant dietary calcium. Oxalate absorption is increased in inflammatory bowel disease (Crohn's disease or ulcerative colitis affecting the small intestine), following small bowel resection, and after gastric bypass surgery (see earlier). However, most urinary oxalate is endogenous in origin and the metabolic

\footnotetext{
3 In proximal or type 2 RTA, citrate excretion may be normal or in creased.
}

An Overview of Renal Stone

Management end-product of glyoxylate. Very high levels of urinary oxalate $(>800 \mu \mathrm{mol} / \mathrm{day})$ occur in primary hyperoxaluria (types I and II), which does not always present in early childhood; high levels ( $>450$ and $<800 \mu \mathrm{mol} /$ day) are seen more commonly in idiopathic hyperoxaluria.

Hyperuricosuria and hyperuricaemia are positively linked to both uric acid and calcium oxalate stone formation (through heterogeneous nucleation) [32]. Hyperuricosuria is most commonly associated with a high purinecontaining (animal protein and beer) diet, uricosuric drugs, increased protein catabolism, and, more recently, the metabolic syndrome. Ten percent of patients with gout have associated hyperuricosuria, and the risk of uric acid stones is proportional to uric acid excretion: only $11 \%$ of patients with uric acid excretion $<1.8 \mathrm{mmol} /$ day have uric acid stones [33], whereas $23 \%$ of those excreting $>3.6 \mathrm{mmol} /$ day, and $50 \%$ of those excreting $>6 \mathrm{mmol} /$ day, have stones [34].

\section{Use of Risk Indices}

Since stone risk is a composite of several risk factors, use of risk indices that combine these risk factors to give a single and predictive score has always been a goal, especially since any intervention can only be judged by rates of stone recurrence. Several risk indices have been proposed [35]: Tiselius risk index, Bonn Risk Index, and calcium oxalate risk index, EQUIL, SEQUIL, and $\mathrm{P}_{\mathrm{sf}}$. All, except for $\mathrm{P}_{\mathrm{sf}}$, have a physico-chemical basis, treating urine as a supersaturated solution with citrate as the main stabilizer or inhibitor. In contrast, $\mathrm{P}_{\mathrm{sf}}$ is based on retrospective observational metabolic data comparing nonstone formers with stone formers. Figures 4 and 5 summarize SEQUIL and $\mathrm{P}_{\text {sf }}$, respectively. These scores (which can be combined) can be used to determine the most significant risk factors in an individual patient and as a guide to medical therapy, including the use and balance of fluid intake and citrate supplements.

\section{Radiological Investigation}

Previously, those presenting with renal colic had an emergency plain X-ray or KUB (kidneys, ureters and bladder). If a stone was identified in the line of the ureters, no further investigation was considered necessary, and appropriate urological treatment was carried out. When there was any doubt about a radio-opacity or none was detected, an intravenous contrast study (pyelography or

Nephron Clin Pract 2010;116:c159-c17 
Fig. 4. The SEQUIL calculation can be used to guide citrate therapy and recommended fluid intake (see text) [61].

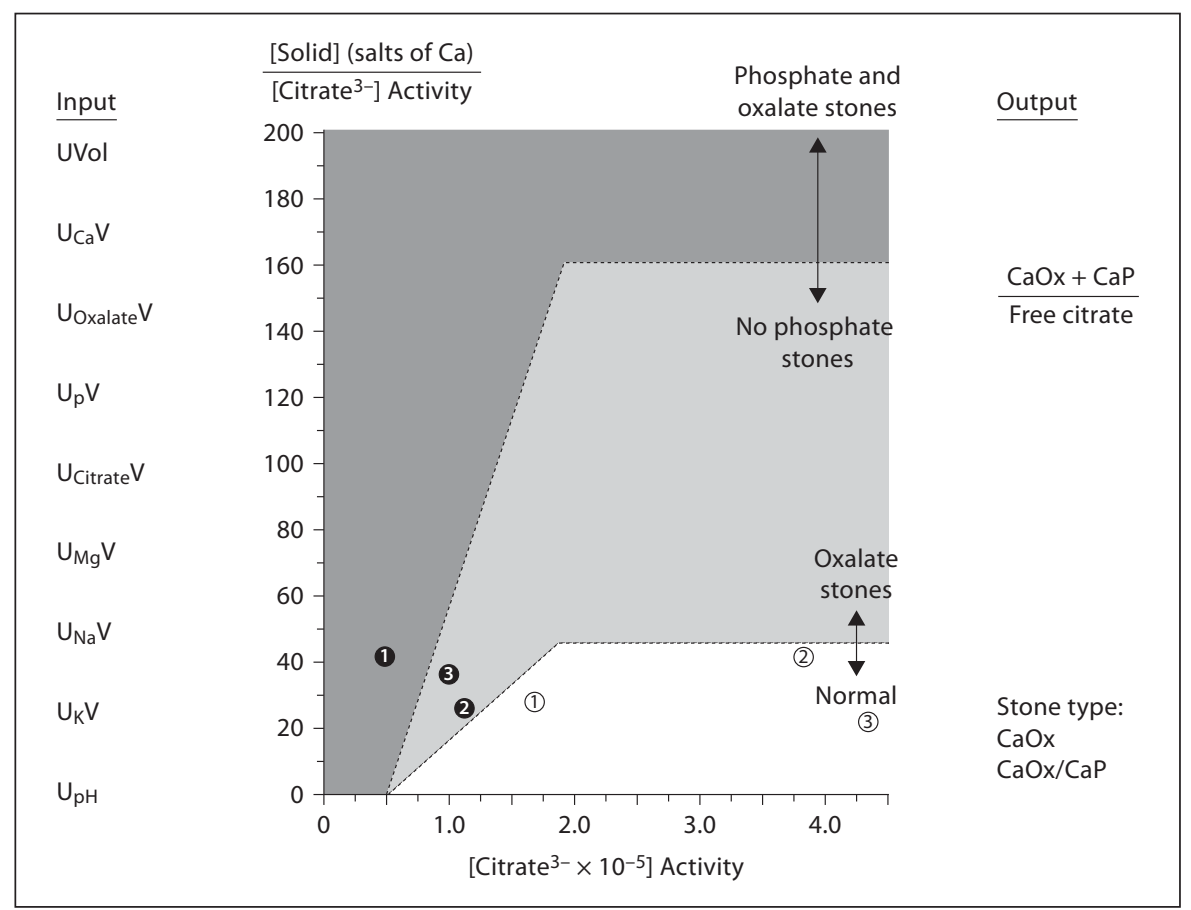

urography, IVP/IVU) was performed. The classic triad of a delayed pyelogram, dense and persistent nephrogram, and dilatation of parts, or all, of the upper urinary tract indicated a ureteric obstruction, usually requiring prompt surgical intervention. However, since the advent of computerized tomography (CT), the non-contrast or unenhanced CT-KUB has rendered IVU obsolete and it is rarely used today. Why is CT-KUB so much better? It can detect and localize almost $100 \%$ of stones, whatever their composition (except some drug-containing stones, e.g. indinavir) or radio-opaqueness on KUB; small stones overlying bony structures can also be missed on KUB. The degree and duration of obstruction can be diagnosed with CT-KUB, as well as abnormally sited stones, and stones in post-operative urinary tracts. Moreover, CTKUB does not usually require use of contrast, thus avoiding the risk of allergic reactions or an acute deterioration in renal function in those with renal impairment. In addition, using the Hounsfield units of image opacity on $\mathrm{CT}$, an estimate of stone composition and 'hardness' can also be made and thus the likelihood of successful fragmentation by lithotripsy.

Ultrasound scanning (USS) is of limited value in the initial investigation and management of renal stones because of its low sensitivity compared with CT-KUB $(<25$ vs. $>95 \%$ ) [36], although it does have a place in following up any identified stones. Recurrent and frequent stone formers usually require periodic radiological surveillance, since there is evidence that asymptomatic stones may dislodge and cause ureteric obstruction; combined USS with KUB is the most convenient way of doing this. Although more sensitive than KUB or USS, CT-KUB has the major disadvantage of its cumulative radiation dose and it should not be repeated too often. The choice and frequency of imaging ought to be guided by the clinical features in consultation with colleagues in radiology and urology.

\section{Surgical Management}

Surgical management of urinary tract stones depends on their size and site, and on any symptoms and signs, particularly of obstruction. Stones can lodge in the proximal, mid- (overlying the sacroiliac joint) or distal ureter. Approximately $70 \%$ of small $(\leq 5 \mathrm{~mm})$ ureteric stones and $50 \%$ of stones $>5$ and $\leq 10 \mathrm{~mm}$ should pass spontaneously; $\alpha$-blocker therapy can increase the rate of stone passage by up to $30 \%$ [37]. With a ureteric stone $>10 \mathrm{~mm}$, and when pain persists despite intramuscular diclofenac or pethidine, and/or if there is renal obstruction, treatment is by endoscopic removal (URS). However, if this is not possible, a ureteric stent or nephrostomy tube is inserted until URS can be carried out. In a patient with an obstructed kidney and signs of infection, relief of ob- 


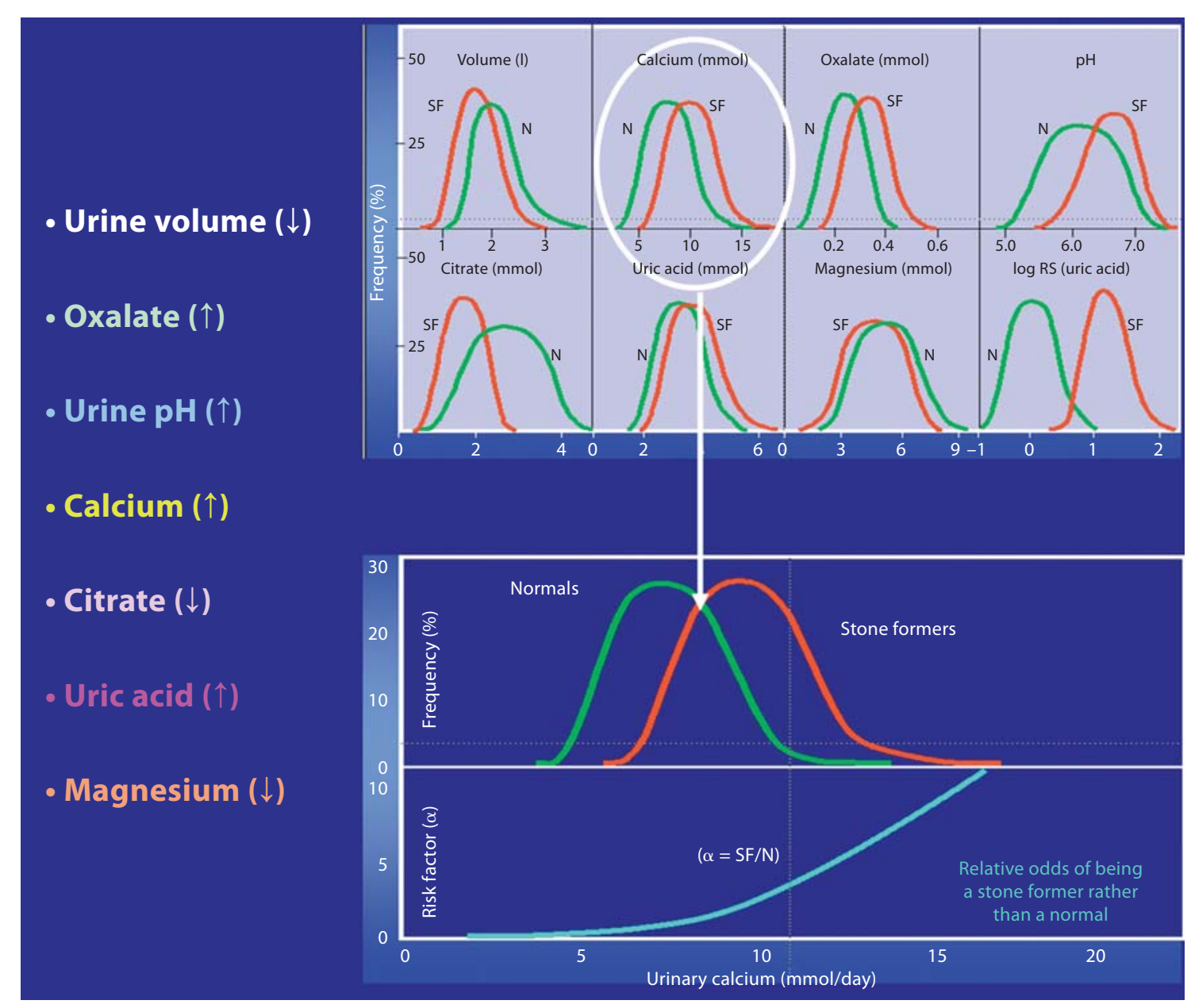

Fig. 5. The $\mathrm{P}_{\mathrm{sf}}$ calculation uses a composite of relative risk (normals versus stone formers) for each of the 7 listed urinary variables. Arrows for each variable indicate direction of increased risk.

struction is an emergency. With small ureteric stones and satisfactory pain control with analgesia, patients can be given a supply of an $\alpha$-blocker and reviewed within 2 weeks. Stones $<10 \mathrm{~mm}$ in the proximal and mid-ureter can also be managed by lithotripsy, but distal ureteric stones of whatever size are better treated by URS [37].

Calyceal and pelvic stones can be managed by lithotripsy, flexible URS and laser removal, or PCNL. As with ureteric stones, the choice depends on size and site, hardness (assessed by CT - see above), intrarenal anatomy, and the patient's symptoms and preference. Patients with asymptomatic stones are usually offered treatment, since if left untreated, over $70 \%$ of stones are likely to increase in size, dislodge and cause symptoms [38]. Lithotripsy can be recommended for stones $<20 \mathrm{~mm}$ in size; a course of treatment involves two or more 30 -min sessions. Contraindications to lithotripsy are pregnancy or taking an- ticoagulants such as warfarin and clopidogrel (aspirin should be stopped 10 days before treatment). Reported success rates for lithotripsy vary from 30 to $100 \%$, depending on how patients are selected, how hard the stone is, and the type of lithotripter used $[39,40]$. Complications of lithotripsy are rare [41], although there have been unusual case reports of post-treatment anti-GBM antibody-positive glomerulonephritis [42, 43], and even a later increase in the incidence of hypertension and diabetes [44]. A stone in a calyceal diverticulum, or a dependent lower pole calyx, can break up, but may not pass. Treating large stones with lithotripsy risks producing multiple stone fragments that can cause ureteric obstruction (socalled 'steinstrasse'), unless a ureteric stent is in place. It can take several weeks to determine if lithotripsy will be successful. Renal stones that do not respond to lithotripsy can be treated by flexible URS if they are small 
( $\sim 3 \mathrm{~mm}$ ), but larger stones $\geq 20 \mathrm{~mm}$, or those in a calyceal diverticulum or lower pole calyx, are better treated by PCNL. Surgical treatment depends on available local expertise and facilities, as well as a patient's preference.

\section{Medical Management}

\section{Fluid Intake and Dietary Modification}

Fluid intake and dietary advice are important interventions in all stone formers and remain first-line in stone management. Controlled trials have shown that increasing urine volume to at least 2 litres a day can reduce recurrence rates by $40-50 \%$ [45]. Fluid intake should include mainly water, and tea or coffee should be taken with some milk (which binds free oxalate). Bear in mind that increasing fluid intake, and thus urine volume, may critically lower urinary citrate concentration, especially if it is already low. Citrus fruits, particularly lemons and limes, may be of some benefit, but the sugar content of many fruit juices is a disadvantage. A calcium intake of $\sim 25$ $\mathrm{mmol} /$ day is the estimated mean on a typical Western diet, whereas oxalate intake is $\sim 1.5 \mathrm{mmol} /$ day. The ratio of dietary oxalate/total calcium is a guide to dietary modifications; in the general population this is around 0.05 . Several studies have shown that low dietary calcium increases the risk of calcium oxalate stones, and stone formers should generally be advised to maintain a normal, and not to reduce, calcium intake. A small reduction in urinary oxalate can significantly reduce the risk of forming calcium oxalate stones (see earlier), therefore, avoiding oxalate-rich foods (spinach, rhubarb, beetroot, soya beans and tofu, nuts, peanut butter, okra, yams, sesame seeds, tahini and chocolate) is justified, even if the contribution of dietary oxalate to urinary oxalate excretion is limited [46]. A reduction in dietary fat intake can decrease urinary oxalate excretion: in 13 patients with disease of the ileum (mainly due to Crohn's disease) who switched from a 100- to a 40-gram fat diet, oxalate excretion decreased slowly, but significantly, up to $50 \%$, if faecal fat excretion fell to $<15 \mathrm{~g} /$ day [47]. In patients with significant hypercalciuria and a high calcium intake (particularly if derived from dairy produce, the more absorbable form), some reduction in dietary calcium with oxalate may be justified. Reducing daily animal protein intake, including fish, red meat and poultry (there is no distinction for stone risk), to $40-50 \mathrm{~g}$ (140-160 $\mathrm{g}$ of animal flesh) per day is recommended in both calcium oxalate and uric acid stone formers, although a low protein diet is not advisable. Replacing animal protein with fresh fruit and vegetables should be encouraged, as this not only reduces urate excretion, but it also alkalinizes the urine; increased potassium intake can also increase urinary citrate excretion. Beer increases urate excretion due to its high content of the purine guanosine, and it should be restricted in uric acid stone formers; non-fortified wines, though uricosuric, have a much smaller effect on urate production and excretion. Increasing dietary potassium and magnesium, if urinary levels are low, and reducing dietary sodium, if intake and excretion are high, are also worthwhile measures and can be achieved by eating a more Mediterranean-style diet, such as the widely publicized DASH (Dietary Approaches to Stop Hypertension) diet [48].

\section{Pharmacological Treatment}

\section{Calcium Oxalate Stones}

Thiazide diuretics can be tried in recurrent calcium oxalate stone formers with idiopathic hypercalciuria. Randomized-controlled trials have shown reductions in stone recurrence rates of up to $70 \%$ with thiazide diuretics [49]. Adverse effects that may offset any benefit are hypokalaemia (associated with reduced citrate excretion), hyperuricaemia, and hyperglycaemia. Use of thiazides in calcium oxalate stone formers without hypercalciuria is unlikely to be beneficial [50]. Citrate supplements have been shown to reduce stone recurrence in idiopathic calcium oxalate stone formers with hypocitraturia and also in those with normal urinary citrate levels [51, 52]. Alkali therapy in the form of potassium or magnesium citrate (40-120 $\mathrm{mmol} /$ day in 2-3 divided doses) can be used to try to boost citrate excretion (to $>3 \mathrm{mmol} / \mathrm{day}$ ) in stone formers with hypocitraturia, but these salts are not always well tolerated. Although sodium citrate is better tolerated, like sodium bicarbonate, it has the disadvantage of an additional sodium load, which may tend to increase calcium excretion. However, by raising urine $\mathrm{pH}$, all alkalis can increase the risk of forming calcium phosphate stones, but less so if given as the potassium salt (see fig. 6). Allopurinol has been shown to benefit recurrent calcium oxalate stone formers who have hyperuricaemia or hyperuricosuria [53], but not those who have normal urate excretion. Allopurinol in doses of 50 or $100 \mathrm{mg}$ daily can be prescribed if dietary recommendations do not reduce urinary urate excretion; doses of $300 \mathrm{mg}$ or more daily are usually required in hyperuricaemic patients. Calcium supplements may be necessary in those with a low calcium intake ( $<15 \mathrm{mmol} /$ day) and high oxalate/total calcium ratio ( $>0.05$ - see earlier); calcium supplements taken with 
Fig. 6. Representative $P_{\text {sf }}$ risk scores for calcium phosphate $(\mathrm{CaP})$ and calcium oxalate $(\mathrm{CaOx})$ stone formation; most stone formers have $\mathrm{P}_{\text {sf }}$ values $>0.5$. Shown here is the effect of giving alkali as potassium or sodium salt. For both $\mathrm{CaP}$ and $\mathrm{CaOx}$ stones, $\mathrm{P}_{\text {sf }}$ values improve significantly when alkali is given as potassium citrate, in contrast to sodium bicarbonate.

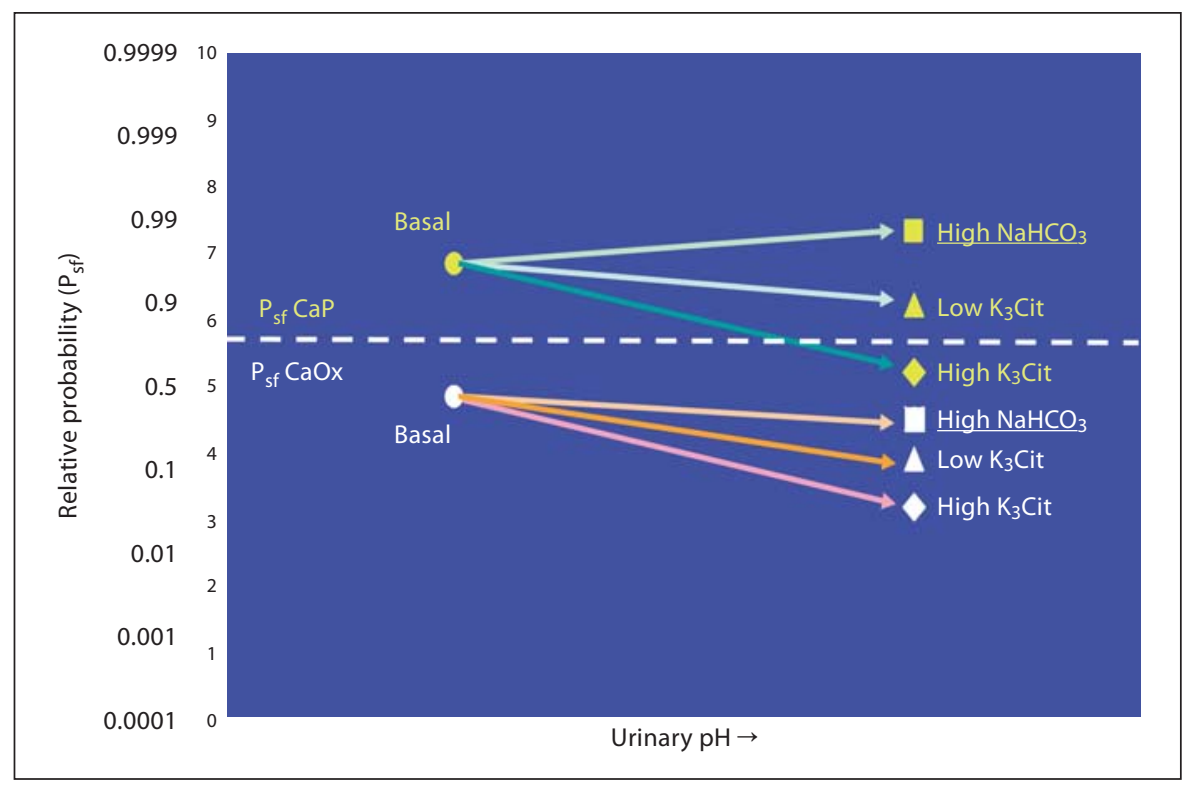

meals may also be helpful in those with enteric hyperoxaluria. Pyridoxine can sometimes reduce oxalate excretion in primary hyperoxaluria (PH1, but not $\mathrm{PH} 2)$, but not in idiopathic hyperoxaluria. Finally, because of the underlying hypothesis that stone formation is the result of initial renal tubular cell injury, which may involve oxidative damage, especially from oxalate, antioxidants such as vitamin E, catechin in green tea, and some flavenoids like quercetin, have been proposed as adjunctive therapy [54], although there is little supporting data in humans.

\section{Uric Acid Stones}

Unlike the other main stone types, uric acid stones can be managed medically. The aim of treatment is to increase the solubility of uric acid in urine and to reduce its concentration. Increasing urine volume to $>2.5-3.0$ 1/day is essential and should be emphasized. Alkalinization of urine may be carried out using citrate or bicarbonate salts given in 2 or 3 daily divided doses. Alkali treatment can be guided by urine $\mathrm{pH}$ to achieve a fasting urine $\mathrm{pH}>6.0$ (a fasting urine $\mathrm{pH}$ of $>7$ can increase the risk of forming calcium phosphate stones). As already mentioned, allopurinol is a useful adjunct in reducing urate excretion. A focus on long-term weight reduction and a low animal protein diet is also worthwhile.

\section{Struvite and Calcium Phosphate Stones}

Struvite, or triple phosphate (calcium, magnesium, ammonium phosphate), stones form in alkaline urine from infection with a urea-splitting organism. Treatment is with antibiotics and sometimes the urease inhibitor acetohydroxamic acid. Pure calcium phosphate stones should always raise the possibility of an underlying defect in renal acid excretion, more specifically dRTA, especially if nephrocalcinosis is also present. This can be detected by acid loading with oral ammonium chloride, or the more convenient furosemide plus fludrocortisone urinary acidification test [55].

\section{Cystine Stones}

Cystine stones are rare but require intensive management to prevent complications and recurrence. Treatment is aimed at reducing the concentration of free cystine (formed from oxidation of the amino acid cysteine) in urine and increasing its solubility. A high fluid intake of around 4-5 litres a day is required, and to drink before going to bed and during the night to maintain a dilute urine overnight. Alkalinization of urine with citrate or bicarbonate will increase cystine solubility, but fasting urine $\mathrm{pH}$ needs to be $>7$, with the attendant risk of calcium phosphate precipitation, unless urine is sufficiently dilute. Twenty-four-hour urine cystine measurements are used to guide therapy: if 24-hour urine cystine concentration remains $>2,000 \mu \mathrm{mol} / \mathrm{l}$, chelation therapy is usually necessary, given as D-penicillamine or Tiopronin $(\alpha$-mercaptopropionylglycine), to reduce free cystine concentration to $<1,000 \mu \mathrm{mol} / 1$ (ideally $<500 \mu \mathrm{mol} / \mathrm{l}$ ). These compounds bind cysteine and prevent formation of less soluble cystine. D-penicillamine is more easily available, but can have serious side effects (agranulocyto- 
sis and proteinuria), and it needs close monitoring and careful dose titration.

Apart from some rare drug-related causes of renal stones, such as triamterene, indinavir and, more recently, lopinavir, investigation and practical management of renal stone disease require a holistic approach. Renal stones do occur more commonly in patients with hypertension, diabetes, and the metabolic syndrome, and their presence could be viewed as yet another cardiovascular risk factor [18]. In fact, the advice that we give and the treatments we recommend are of wider cardiovascular benefit, which is worth reinforcing in our patients.

\section{References}

1 Buchholz NP, Abbas F, Afzal M, Khan R, Rizvi I, Talati J: The prevalence of silent kidney stones - an ultrasonographic screening study. J Pak Med Assoc 2003;53:24-25.

-2 Indridason OS, Birgisson S, Edvardsson VO, Sigvaldason H, Sigfusson N, Palsson R: Epidemiology of kidney stones in Iceland: a population-based study. Scand J Urol Nephrol 2006;40:215-220

- 3 Soucie JM, Thun MJ, Coates RJ, McClellan W, Austin H: Demographic and geographic variability of kidney stones in the United States. Kidney Int 1994;46:893-899.

-4 Stamatiou KN, Karanasiou VI, Lacroix RE, Kavouras NG, Papadimitriou VT, Chlopsios C, Lebren FA, Sofras F: Prevalence of urolithiasis in rural Thebes, Greece. Rural Remote Health 2006;6:610.

5 Ljunghall S, Danielson BG: A prospective study of renal stone recurrences. Br J Urol 1984;56:122-124.

-6 Hosking DH, Erickson SB, Van den Berg CJ, Wilson DM, Smith LH: The stone clinic effect in patients with idiopathic calcium urolithiasis. J Urol 1983;130:1115-1118.

7 Pearle MS, Roehrborn CG, Pak CY: Metaanalysis of randomized trials for medical prevention of calcium oxalate nephrolithiasis. J Endourol 1999;13:679-685.

8 Bhuskute NM, Yap WW, Wah TM: A retrospective evaluation of Randall's plaque theory of nephrolithiasis with CT attenuation values. Eur J Radiol 2009;72:470-472.

-9 Low RK, Stoller ML: Endoscopic mapping of renal papillae for Randall's plaques in patients with urinary stone disease. J Urol 1997; 158:2062-2064

- 10 Asselman M, Verhulst A, De Broe ME, Verkoelen CF: Calcium oxalate crystal adherence to hyaluronan-, osteopontin-, and CD44-expressing injured/regenerating tubular epithelial cells in rat kidneys. J Am Soc Nephrol 2003; 14:3155-3166.

11 Randall A: Recent advances in knowledge relating to the formation, recognition and treatment of kidney calculi. Bull NY Acad Med 1944;20:473-484.

12 Randall A: The origin and growth of renal calculi. Ann Surg 1937;105:1009-1027.

13 Khan SR: Calcium oxalate crystal interaction with renal tubular epithelium, mechanism of crystal adhesion and its impact on stone development. Urol Res 1995;23:71-79.
14 Asselman M, Verhulst A, Van Ballegooijen ES, Bangma CH, Verkoelen CF, De Broe ME: Hyaluronan is apically secreted and expressed by proliferating or regenerating renal tubular cells. Kidney Int 2005;68:71-83.

15 Carr G, Simmons NL, Sayer JA: Disruption of clc-5 leads to a redistribution of annexin A2 and promotes calcium crystal agglomeration in collecting duct epithelial cells. Cell Mol Life Sci 2006;63:367-377.

16 Curhan GC, Willett WC, Rimm EB, Spiegelman D, Stampfer MJ: Prospective study of beverage use and the risk of kidney stones. Am J Epidemiol 1996;143:240-247.

17 Curhan GC, Willett WC, Speizer FE, Spiegelman D, Stampfer MJ: Comparison of dietary calcium with supplemental calcium and other nutrients as factors affecting the risk for kidney stones in women. Ann Intern Med 1997;126:497-504.

18 Sakhaee K: Nephrolithiasis as a systemic disorder. Curr Opin Nephrol Hypertens 2008; 17:304-309.

19 Taylor EN, Stampfer MJ, Curhan GC: Diabetes mellitus and the risk of nephrolithiasis. Kidney Int 2005;68:1230-1235.

20 Daudon M, Traxer O, Conort P, Lacour B, Jungers P: Type 2 diabetes increases the risk for uric acid stones. J Am Soc Nephrol 2006; 17:2026-2033.

21 Sakhaee K: Recent advances in the pathophysiology of nephrolithiasis. Kidney Int 2009;75:585-595.

22 Kaufman DW, Kelly JP, Curhan GC, Anderson TE, Dretler SP, Preminger GM, Cave DR: Oxalobacter formigenes may reduce the risk of calcium oxalate kidney stones. J Am Soc Nephrol 2008;19:1197-1203.

23 Hatch M, Cornelius J, Allison M, Sidhu H, Peck A, Freel RW: Oxalobacter sp. reduces urinary oxalate excretion by promoting enteric oxalate secretion. Kidney Int 2006;69: 691-698.

24 Sinha MK, Collazo-Clavell ML, Rule A, Milliner DS, Nelson W, Sarr MG, Kumar R, Lieske JC: Hyperoxaluric nephrolithiasis is a complication of Roux-en-Y gastric bypass surgery. Kidney Int 2007;72:100-107.

25 Caldwell EF, Mayor LR, Thomas MG, Danpure CJ: Diet and the frequency of the alanine:glyoxylate aminotransferase Pro${ }^{11}$ Leu polymorphism in different human populations. Hum Genet 2004;115:504-509.
26 Jiang Z, Asplin JR, Evan AP, Rajendran VM, Velazquez H, Nottoli TP, Binder HJ, Aronson PS: Calcium oxalate urolithiasis in mice lacking anion transporter SLC26A6. Nat Genet 2006;38:474-478.

27 Prie D, Beck L, Silve C, Friedlander G: Hypophosphatemia and calcium nephrolithiasis. Nephron Exp Nephrol 2004;98:e50-e54.

$>28$ Vezzoli G, Tanini A, Ferrucci L, Soldati L, Bianchin C, Franceschelli F, Malentacchi C, Porfirio B, Adamo D, Terranegra A, Falchetti A, Cusi D, Bianchi G, Brandi ML: Influence of calcium-sensing receptor gene on urinary calcium excretion in stone-forming patients. J Am Soc Nephrol 2002;13:2517-2523.

29 Remer T, Manz F: Potential renal acid load of foods and its influence on urine $\mathrm{pH}$. J Am Diet Assoc 1995;95:791-797.

- 30 Cupisti A, Morelli E, Lupetti S, Meola M, Barsotti G: Low urine citrate excretion as main risk factor for recurrent calcium oxalate nephrolithiasis in males. Nephron 1992; 61:73-76.

31 Curhan GC, Willett WC, Speizer FE, Stampfer MJ: Twenty-four-hour urine chemistries and the risk of kidney stones among women and men. Kidney Int 2001;59:2290-2298.

32 Dussol B, Verdier JM, Goff JM, Berthezene P, Berland Y: Artificial neural networks for assessing the risk factors for urinary calcium stones according to gender and family history of stone. Scand J Urol Nephrol 2007;41: 414-418.

-33 Hall AP, Barry PE, Dawber TR, McNamara PM: Epidemiology of gout and hyperuricemia. A long-term population study. Am J Med 1967;42:27-37.

34 Yu T, Gutman AB: Uric acid nephrolithiasis in gout. Predisposing factors. Ann Intern Med 1967;67:1133-1148.

35 Sutton RA: The use of risk indices: do they predict recurrence? Urol Res 2006;34:122125.

36 Fowler KA, Locken JA, Duchesne JH, Williamson MR: US for detecting renal calculi with nonenhanced CT as a reference standard. Radiology 2002;222:109-113.

- 37 Preminger GM, Tiselius HG, Assimos DG, Alken P, Buck AC, Gallucci M, Knoll T, Lingeman JE, Nakada SY, Pearle MS, Sarica K, Turk C, Wolf JS Jr: 2007 Guideline for the management of ureteral calculi. Eur Urol 2007;52:1610-1631. 
>38 Burgher A, Beman M, Holtzman JL, Monga M: Progression of nephrolithiasis: long-term outcomes with observation of asymptomatic calculi. J Endourol 2004;18:534-539.

39 Lingeman JE, Lifshitz DA, Evan AP: Surgical management of urinary lithiasis; in Walsh, Retik, Waughan, Wein (eds): Campbell's Urology. Philadelphia, Saunders, 2009, pp 3405-3407.

40 Perks AE, Gotto G, Teichman JM: Shock wave lithotripsy correlates with stone density on preoperative computerized tomography. J Urol 2007;178:912-915.

-41 Coptcoat MJ, Webb DR, Kellett MJ, Fletcher MS, McNicholas TA, Dickinson IK, Whitfield $\mathrm{HN}$, Wickham JE: The complications of extracorporeal shockwave lithotripsy: management and prevention. Br J Urol 1986;58: 578-580.

-42 Xenocostas A, Jothy S, Collins B, Loertscher R, Levy M: Anti-glomerular basement membrane glomerulonephritis after extracorporeal shock wave lithotripsy. Am J Kidney Dis 1999;33:128-132.

43 Iwamoto I, Yonekawa S, Takeda T, Sakaguchi M, Ohno T, Tanaka H, Hasegawa H, Imada A, Horiuchi A, Umekawa T, Kurita T: Antiglomerular basement membrane nephritis after extracorporeal shock wave lithotripsy. Am J Nephrol 1998;18:534-537.

44 Krambeck AE, Gettman MT, Rohlinger AL, Lohse CM, Patterson DE, Segura JW: Diabetes mellitus and hypertension associated with shock wave lithotripsy of renal and proximal ureteral stones at 19 years of follow-up. J Urol 2006;175:1742-1747.
45 Borghi L, Meschi T, Amato F, Briganti A, Novarini A, Giannini A: Urinary volume, water and recurrences in idiopathic calcium nephrolithiasis: a 5-year randomized prospective study. J Urol 1996;155:839-843.

46 Taylor EN, Curhan GC: Determinants of 24hour urinary oxalate excretion. Clin J Am Soc Nephrol 2008;3:1453-1460.

$\checkmark 47$ Andersson H, Jagenburg R: Fat-reduced diet in the treatment of hyperoxaluria in patients with ileopathy. Gut 1974;15:360-366.

48 Taylor EN, Fung TT, Curhan GC: DASH style diet associates with reduced risk for kidney stones. J Am Soc Nephrol 2009;20: 2253-2259.

49 Ohkawa M, Tokunaga S, Nakashima T, Orito M, Hisazumi H: Thiazide treatment for calcium urolithiasis in patients with idiopathic hypercalciuria. Br J Urol 1992;69:571-576.

50 Wolf H, Brocks P, Dahl C: Do thiazides prevent recurrent idiopathic renal calcium oxalate stones? Proc Eur Dial Transplant Assoc 1983;20:477-480.

51 Ettinger B, Pak CY, Citron JT, Thomas C, Adams-Huet B, Vangessel A: Potassiummagnesium citrate is an effective prophylaxis against recurrent calcium oxalate nephrolithiasis. J Urol 1997;158:2069-2073.

52 Hofbauer J, Hobarth K, Szabo N, Marberger M: Alkali citrate prophylaxis in idiopathic recurrent calcium oxalate urolithiasis - a prospective randomized study. Br J Urol 1994;73:362-365.

-53 Ettinger B, Tang A, Citron JT, Livermore B, Williams T: Randomized trial of allopurinol in the prevention of calcium oxalate calculi. N Engl J Med 1986;315:1386-1389.
54 Park HK, Jeong BC, Sung MK, Park MY, Choi EY, Kim BS, Kim HH, Kim JI: Reduction of oxidative stress in cultured renal tubular cells and preventive effects on renal stone formation by the bioflavonoid quercetin. J Urol 2008;179:1620-1626.

55 Walsh SB, Shirley DG, Wrong OM, Unwin RJ: Urinary acidification assessed by simultaneous furosemide and fludrocortisone treatment: an alternative to ammonium chloride. Kidney Int 2007;71:1310-1316.

-56 Curhan GC, Willett WC, Rimm EB, Stampfer MJ: A prospective study of dietary calcium and other nutrients and the risk of symptomatic kidney stones. N Engl J Med 1993; 328:833-838.

57 Kaul P, Sidhu H, Sharma SK, Nath R: Calculogenic potential of galactose and fructose in relation to urinary excretion of lithogenic substances in vitamin $\mathrm{B}_{6}$ deficient and control rats. J Am Coll Nutr 1996;15:295-302.

58 Holmes RP, Goodman HO, Assimos DG: Contribution of dietary oxalate to urinary oxalate excretion. Kidney Int 2001;59:270276.

59 Saldana TM, Basso O, Darden R, Sandler DP: Carbonated beverages and chronic kidney disease. Epidemiology 2007;18:501-506.

60 Robertson WG: Renal stones in the tropics. Semin Nephrol 2003;23:77-87.

61 Györy AZ, Ashby R: Equilibrium versus supersaturated urine hypothesis in calcium salt urolithiasis: a new theoretical and practical approach to a clinical problem. Scan Microsc 1999;13:261-265.

\title{
Editorial Comment
}

\author{
M. El Nahas, Sheffield
}

This is a most timely and comprehensive review on kidney stone disease. It covers aspects from epidemiology, genetics, pathophysiology to management. It gives clear guidance on management approaches based on composition but also on stone size with emphasis on the respective merits of ESWL, endoscopic and surgical removal. Medical management revisits and updates dietary recommendations. Stone management often requires a holistic and multidisciplinary approach. This was recently highlighted in the excellent report from the SIUT Centre in Karachi promoting the need to open more specialized stone clinics in areas where stone disease is highly prevalent [1]. Kidney stone disease is highly prevalent in emerging economies and is likely to increase globally with the ongoing epidemic of obesity [2]. Nephrologists worldwide need therefore to familiarise themselves with aspects of diagnosis and management of kidney stone disease; the review by Johri et al. offers an excellent update.

\section{References}

Hussain M, Rizvi SA, Askari H, Sultan G, Lal M, Ali B, Naqvi SA: Management of stone disease: 17 years' experience of a stone clinic in a developing country. J Pak Med Assoc 2009;59:843-846.

2 Semins MJ, Shore AD, Makary MA, Magnuson T, Johns R, Matlaga BR: The association of increasing body mass index and kidney stone disease. J Urol 2010;183:571-575. 